\title{
Examining the utility of national indicators of relative age disadvantage in Europe
}

\author{
Liat Ayalon $^{1} \cdot$ Klaus Rothermund ${ }^{1}$
}

Published online: 29 December 2017

(c) Springer-Verlag GmbH Germany, part of Springer Nature 2017

\begin{abstract}
We introduce new indicators measuring relative age disadvantage of older compared with younger people at a national level. Drawing on data from 29 European countries, the study demonstrates that there is no consistent relative old age disadvantage with regard to the four indicators selected: satisfaction in life, perceived prejudice, perceived access to health services, and subjective income. Relative age disadvantages (i.e. the status of those aged $30-45$ divided by the status of older adults aged 60-75) correlated negatively with overall levels of happiness at the country level. Multi-level analyses revealed cross-level interactions, indicating that countries with higher levels of relative age disadvantage were characterized by a more negative relation between age and happiness at the individual level. Our findings highlight a need to further investigate relative age disadvantages for understanding, describing, and potentially changing the situation of older people in modern societies.
\end{abstract}

Keywords Age inequality - Age discrimination - National indicators $\cdot$ Relative disadvantage

\section{Introduction}

In 1948, the United Nations General Assembly adopted a Universal Declaration of Human Rights, emphasizing the fact that all individuals have the same rights: "without

Responsible Editor: H.-W. Wahl.

Liat Ayalon

liatayalon0@gmail.com

1 Bar Ilan University, Ramat Gan, Israel distinction of any kind, such as race, colour, sex, language, religion, political or other opinion, national or social origin, property, birth or other status" (Article 2, http://www.un. org/en/documents/udhr/). Seven decades later, age is still not an explicit part of a UN declaration (Mégret 2011). This is surprising given the fact that in 2016, for the first time in human history, older adults have outnumbered children, globally. This is also surprising given staggering statistics, which have shown that ageism (i.e. discrimination based on age) is the most prevalent type of discrimination experienced by Europeans (Ayalon 2014). Whereas not everyone is likely to experience discrimination based on race or gender, everyone is susceptible to ageism, if they live long enough (Palmore 2015).

Although ageism can be directed towards both young and old, it has been more extensively studied as discrimination towards older adults because of their age. The detrimental effects of ageism or age inequality are substantial. In the health care system, older adults are less likely to be offered expensive or innovative treatments (Shortt 2001) and are often excluded from clinical trials, even for age-related conditions (Cherubini et al. 2010). In the media, older women, in particular, are considered unattractive and are not likely to be represented (Jermyn 2013). The judicial-legal system tends to paternalistically protect older adults, rather than preserving their autonomy (McNally and Lahey 2015). In the workforce, older adults are less likely to find a job and are arbitrarily forced to retire at a certain age (MacGregor 2006). Finally, at the individual level, internalized age-related stereotypes play a substantial role in health and well-being (Lakra et al. 2012; Levy et al. 2002; Westerhof et al. 2014) as well as in the ageing process (Kornadt and Rothermund 2015; KotterGrühn and Hess 2012). 
It is important to note, however, that ageism is not the only source of social inequality between young and old. For instance, some age-related differences are due to cohort effects. Because as a cohort, the older generation had fewer opportunities to acquire higher education, this generation is systematically disadvantaged compared with the younger generation (Lynch 2003). Another source of disadvantage can be found in the domain of health. Physical health tends to deteriorate so that old age is associated with physical disability (Chatterji et al. 2015). This too represents a source of inequality, which is not necessarily due to agebased discrimination.

The need for national level indicators of age inequality global measures of inequality at the national level are abundant and have shown to be associated with poor health and social outcomes (Hosseinpoor et al. 2015; Wilkinson and Pickett 2006). The advantage of these national level indicators is that they can direct policies and public opinion by pointing to gaps between different groups or nations or by delineating changes over time.

The exact dimensions used to portray inequality are determined based on the specific population groups in question (e.g. gender, race, or age inequalities) and the specific rationale or theoretical stand (Burchardt 2006). For instance, gender has received considerable attention, with the United Nations (UN), the World Health Organization (WHO), the organization for co-operation and development (OECD), and other bodies developing and validating various indicators (e.g. gender inequality index and gender equality) to measure and compare gender inequality between different countries (Geske Dijkstra 2006; Jütting et al. 2008). Indicators used to measure the construct of gender inequality include maternal mortality rate, adolescent birth rate, and labour force participation of men and women. This clearly confirms the unanimous interest in gender inequality as a significant phenomenon that should be identified and addressed, but the multiplicity of different indicators also attests to a lack of consensus regarding what constitutes indicators of gender (in)equality.

In the past decade, there also has been an increasing interest in national indices which portray the situation of older adults in society in order to impact public policy and planning for older adults. The global AgeWatch index (GAWI) was developed by HelpAge International to rank countries according to the social and economic well-being of older adults (Zaidi 2014). A related index is the active ageing index (AAI). The AAI is a tool that assesses the potential of older adults for active and healthy ageing in Europe. The measure consists of four domains: employment (stratified by age group), participation in society (e.g. voluntary activity, care to children and grandchildren), independent and secured living (e.g. physical exercise, access to health services), and capacity and enabling environment for active ageing (e.g. use of information and computer technology, mental well-being, remaining life expectancy at 55). The measure indicates the potential of older adults to live active and productive lives and also allows for a comparative analysis based on gender (Boudiny 2013; Zaidi 2014). Although indices like these are highly valuable for pointing attention to the status of living conditions of older adults at the macro-level, they lack a focus on age inequalities within a particular country. These indices address the end product, that is, the overall status of older adults in society, but fail to provide a relative perspective of older adults in comparison with younger populations within the same society. Hence, these are not indicators of age inequality or relative disadvantage, but rather indicators of the global status of older adults' living conditions in a society.

The present study adds to the current discussion on national indicators of inequality by pointing to withincountry age inequalities and relative disadvantage of older people as potentially important predictors and determinants of the status of older adults in society. Our theoretical starting point is guided by the finding that inequalities at the national level hamper social mobility. The burden of relative deprivation often results in negative psychological consequences, which in return influence poor social and health outcomes for disadvantaged groups (Wilkinson and Pickett 2007). This follows from an ecological model, which suggests that to achieve well-being, the fulfilment of personal (e.g. meaning, growth), relational (e.g. respect for diversity, democratic participation), and collective (e.g. welfare policies, access to services) needs has to be possible (Prilleltensky 2008). Therefore, we argue that withincountry indicators of relative age disadvantage should provide valuable information for explaining and predicting the status of older adults in society.

The rationale of the study is twofold: first, our aim is to develop and compute country-level indicators of relative disadvantage of older people. For this purpose, we compare the status of older adults between the ages of 60 and 75 in a country to those at the ages of 30 and 45 on four highly important dimensions. These dimensions broadly reflect the personal, relational, and collective needs proposed by Prilleltensky (2008). The first indicator is satisfaction in life. It represents a proxy of personal needs. A second indicator is perceived age discrimination. This indicator represents relational needs. Two additional indicators represent collective needs: subjective income and access to services.

We specifically selected four indicators of subjective rather than objective nature, given the clear distinction between the two. One might experience discrimination, but not be aware of it or not wish to acknowledge the presence of discrimination (Ayalon 2016; Voss et al. 2016), which is 
why the perception of age discrimination is often more closely linked to negative outcomes (Schermuly et al. 2013; Yuan 2007).

By selecting only indicators of potential old age disadvantage that are based on self-report, we acknowledge the importance of subjectivity in the experience of old age inequality and ensure that the indicators share a common overall denominator. It is important to note that these indicators only represent a preliminary attempt to identify available and meaningful indicators, which may contribute to older adults' health and well-being.

We chose two age groups (30-45 vs. 60-75), because of the inverse U-shaped distribution of the relationship between age and social status and power in society (Eaton et al. 2009). Consistently, this inverse relationship is also apparent with regard to well-being (Blanchflower and Oswald 2008). Those in the ages between 30 and 45 represent a group that has already gained status and social power, but has not yet gone through physical and functional declines that occur with age. The older group of individuals in the ages between 60 and 75 , on the other hand, has already started a gradual decline of social status and power. It is important to note, however, that this categorization into two distinct age groups is somewhat arbitrary. There are no clear guidelines to define middle age or even old age in a consistent way across different countries (Ayalon et al. 2014; Lachman et al. 2015). It should also be noted that we chose the two age groups in order to obtain indicators that are particularly sensitive for old age disadvantage. For capturing relative disadvantage of young adults, it would probably be better to compare younger and middle-aged adults.

By averaging across four indicators of relative disadvantage and obtaining a ratio which represents the status of the younger group divided by that of the old group, we obtain a global index of relative age disadvantage for older people within a country (relative disadvantage old $_{\text {). Such an }}$ indicator provides valuable information as it allows for cross-country comparisons and at the same time reflects age-related comparisons within a single country.

We tested the explanatory power of this indicator of relative age disadvantage in predicting happiness in the general population. For this purpose, we computed additional age-matched indices of overall quality of living conditions within a country by adding the mean for the absolute status of the groups of the 60-75-year-olds and the 30-45-year-olds, on the same four dimensions. Averaging across these four indicators resulted in an age-matched indicator reflecting the overall level of quality of living conditions in a country (level age-matched $_{\text {ag }}$. We also included the AgeWatch index as a macro-level indicator, which represents the social and economic well-being of older adults, as a comparative rank across countries (Zaidi 2014).
We relied on these predictors at the national level to explain happiness at the individual level. Happiness is an emotional state, which is considered by the World Health Organization as an important aspect of well-being. For instance, in recent years, several countries have realized that happiness is as important or even more important than gross domestic product, leading some countries to measure happiness as an indicator of prosperity (Vaillant 2011).

Given the substantial body of literature on the negative impact of inequalities at the societal level (Rathmann et al. 2015), the core hypotheses were that the relative disadvantage of older people predicts happiness at the individual level, over and above general age-matched levels of living conditions within a country or the AgeWatch index. We further examined potential cross-level interactions between chronological age at the individual level and the macrolevel predictors. We expected to find an interaction effect between age and relative age disadvantage, so that higher relative age disadvantage would be particularly detrimental for older adults.

\section{Methods}

Data were obtained from the fourth wave of the European Social Survey (ESS) (ESS 2008). The ESS is a cross-national survey, which is conducted every other year, using face-to-face interviews. The survey measures attitudes, beliefs, and behaviours. The present study is based on data available from 29 countries.

Macro-level indicators four subjective dimensions were used in the construction of relative old age disadvantage and age-matched average levels of living conditions:

(a) Satisfaction in life respondents were asked, "All things considered, how satisfied are you with your life as a whole nowadays?" $0=$ extremely dissatisfied; $10=$ extremely satisfied. The intra-class correlation (ICC) of this variable was .17 , indicating that $17 \%$ of the variability is attributed to the country level.

(b) Exposure to prejudice respondents were asked the following three questions:

1. "How often in the past year, anyone has shown prejudice against you or treated you unfairly because of your age?" $0=$ never; $4=$ very often.

2. "And, how often, if at all, in the past year have you felt that someone showed you a lack of respect because of your age, for instance, by ignoring or patronizing you?" $0=$ never; $4=$ very often. 
3. "In particular, how often in the past year has someone treated you badly because of your age, for example, by insulting you, abusing you, or refusing your services?" $0=$ never; $4=$ very often.

4. A composite mean score was calculated, with a higher score indicating greater perceived discrimination. Chronbach's alpha $=.84$. The ICC of this indicator was .04.

(c) Access to health services respondents were asked: "During the next 12 months, how likely is it that you will not receive the health care you really need if you become ill?" Very likely $=1$; not at all likely $=4$. The ICC of this indicator was .15.

(d) Subjective income respondents were asked: "Which of the descriptions comes closest to how you feel about your household's income nowadays?" $1=$ finding it very difficult on present income; 4 = living comfortably on present income. The ICC of this indicator was .25 .

To obtain indicators of within-country relative age disadvantage, we divided the status of those aged $30-45$ by the status of older adults aged 60-75. A score larger than one indicates that older adults are doing worse compared with younger adults. We then computed a single indicator of relative age disadvantage for each country by $z$-standardizing the four domain-specific indicators and averaging across these four $z$-scores. Because a higher score on the exposure to prejudice indicator indicates a worse situation, we divided the status of those aged $60-75$ by those aged $30-45$ in the creation of this indicator.

To obtain age-matched indicators of average levels of living conditions for the four dimensions, we computed the mean of the status of older adults aged 60-75 and the status of those aged 30-45. A single indicator of age-matched overall quality of living conditions within a country was computed by averaging across the four $z$-standardized level indicators for the young and old age groups. Because a higher score on the exposure to prejudice indicator indicates a worse situation, the sign of this variable was reversed in the calculation of the overall score.

The AgeWatch index represents the social and economic well-being of older adults in a country compared to other countries (AgeInternational 2015). A higher score indicates worse status of older adults in a particular country.

\section{Micro-level outcome}

Happiness respondents were asked: "taking all things together, how happy would you say you are?" $0=$ extremely unhappy; $10=$ extremely happy.

\section{Micro-level covariates}

Several demographic variables were included as potential covariates at the micro-level: age, gender $(0=$ woman; $1=$ man), and years of education. These covariates were selected because of their known associations with happiness (Dahlin and Härkönen 2013; Hartog and Oosterbeek 1998; Snyder 2015).

Statistical analyses first, we computed descriptive statistics in order to report domain-specific indicators of relative old age disadvantage (RD), age-matched quality of living conditions $(L)$, the AgeWatch index, and average scores of happiness by country. Next, we conducted correlational analyses of macro-level predictors and the outcome variable at the macro-level. Subsequently, we conducted multi-level regression analyses with happiness as an outcome variable at the individual level. The multilevel analyses were conducted in several stages: (a) an unconditional model was constructed to evaluate the overall variance accounted for by the macro-level (ICC); (b) a model with a random intercept and micro-level covariates was examined: age, gender, and education were included as micro-level covariates; (c) a model with a random intercept and micro-level covariates and a random slope with age serving as a potential predictor was examined; (d) a model with a random intercept and a random slope with micro- and macro-level predictors was constructed; relative age disadvantage, age-matched quality of living conditions, and the AgeWatch index were included as potential macro-level predictors; finally, (e) potential cross-level interactions between age at the micro-level and the three macro-level predictors were examined.

Macro-level predictors were centred on their grand mean, and all continuous micro-level indicators were centred on the country mean. Analyses were weighted using post-stratification weights provided by the ESS. In an additional sensitivity analysis, we entered age-squared into the model in order to assess for a quadratic relationship between age and happiness. Because age-squared was a non-significant predictor of the random intercept, we did not pursue this hypothesis further.

\section{Results}

Descriptive statistics Table 1 displays values of the macrolevel variables: (a) the relative age disadvantage indices $\left(\mathrm{RD}_{x}\right)$, (b) the average age-matched levels of living conditions in the country indices $\left(L_{x}\right)$, and (c) the AgeWatch index. It also presents the micro-level outcome, happiness, aggregated at the macro-level. As can be seen, there was no consistent pattern across countries with regard to relative age disadvantage. 
Table 1 Country-level indicators of relative age disadvantage (relative disadvantage $R D$ ), age-matched quality of living conditions (level $L$ ), AgeWatch index score, and happiness $(N=29)$

\begin{tabular}{|c|c|c|c|c|c|c|c|c|c|c|}
\hline Country & $\mathrm{RD}_{\text {satisfaction }}$ & $\mathrm{RD}_{\text {prejudice }}$ & $\mathrm{RD}_{\text {income }}$ & $\mathrm{RD}_{\text {access }}$ & $L_{\text {satisfaction }}$ & $L_{\text {prejudice }}$ & $L_{\text {income }}$ & $L_{\text {access }}$ & AgeWatch & Happiness \\
\hline Belgium & .98 & .85 & 1.02 & .98 & 7.26 & .51 & 3.06 & 3.29 & 24 & 7.60 \\
\hline Bulgaria & 1.20 & 1.82 & 1.18 & 1.02 & 4.21 & .53 & 1.97 & 2.56 & 49 & 5.55 \\
\hline Croatia & 1.10 & .71 & 1.13 & 1.09 & 6.27 & .38 & 2.78 & 2.73 & 61 & 6.89 \\
\hline Czech Rep. & 1.06 & 1.41 & 1.07 & 1.06 & 6.52 & .95 & 2.70 & 2.90 & 22 & 6.90 \\
\hline Cyprus & 1.00 & 2.41 & 1.09 & 1.06 & 7.03 & .35 & 2.79 & 3.27 & 30 & 7.51 \\
\hline Denmark & .98 & 1.13 & 1.00 & .99 & 8.57 & .26 & 3.61 & 3.14 & 11 & 8.34 \\
\hline Estonia & 1.04 & 1.49 & 1.05 & 1.00 & 6.11 & .43 & 2.73 & 2.87 & 23 & 6.74 \\
\hline Finland & 1.02 & .88 & 1.00 & 1.02 & 7.97 & .46 & 3.10 & 3.28 & 14 & 8.01 \\
\hline France & 1.01 & .88 & .96 & .96 & 6.23 & .52 & 3.19 & 3.14 & 16 & 7.20 \\
\hline Germany & .96 & 1.02 & .97 & .97 & 6.90 & .35 & 3.11 & 3.10 & 4 & 7.22 \\
\hline Greece & 1.07 & 1.56 & 1.12 & 1.01 & 5.92 & .49 & 2.37 & 3.13 & 79 & 6.69 \\
\hline Hungary & 1.01 & 1.52 & .98 & 1.00 & 5.38 & .43 & 2.45 & 2.73 & 39 & 5.89 \\
\hline Ireland & .88 & .97 & .87 & .94 & 7.22 & .40 & 3.10 & 2.86 & 15 & 7.51 \\
\hline Israel & 1.09 & 1.22 & .99 & 1.02 & 7.22 & .58 & 2.76 & 3.20 & 18 & 7.62 \\
\hline Latvia & 1.11 & 2.06 & 1.13 & 1.13 & 5.84 & .45 & 2.24 & 2.27 & 35 & 6.46 \\
\hline Netherlands & 1.00 & .76 & .98 & 1.01 & 7.61 & .42 & 3.36 & 3.24 & 6 & 7.82 \\
\hline Norway & 1.02 & .94 & .96 & .97 & 7.91 & .27 & 3.55 & 3.27 & 2 & 7.99 \\
\hline Poland & 1.20 & 1.57 & 1.12 & 1.08 & 6.53 & .41 & 2.71 & 2.84 & 32 & 7.14 \\
\hline Portugal & 1.11 & 1.32 & 1.08 & 1.07 & 5.65 & .27 & 2.48 & 2.81 & 38 & 6.72 \\
\hline Romania & 1.15 & 1.40 & 1.12 & 1.04 & 5.82 & .79 & 2.35 & 2.50 & 45 & 6.15 \\
\hline Russia & 1.18 & 1.75 & 1.20 & 1.21 & 5.06 & .79 & 2.13 & 2.19 & 65 & 6.21 \\
\hline Slovakia & 1.01 & 1.30 & 1.06 & 1.02 & 6.37 & .68 & 2.65 & 3.11 & 40 & 6.76 \\
\hline Slovenia & 1.06 & .95 & 1.07 & 1.04 & 6.88 & .39 & 3.21 & 3.05 & 26 & 7.25 \\
\hline Spain & 1.04 & 1.19 & 1.03 & 1.00 & 7.19 & .47 & 2.98 & 3.57 & 25 & 7.69 \\
\hline Sweden & .97 & .54 & .99 & .99 & 7.88 & .35 & 3.50 & 3.27 & 3 & 7.83 \\
\hline Switzerland & .94 & .96 & 1.00 & .96 & 7.92 & .36 & 3.36 & 3.48 & 1 & 8.00 \\
\hline Turkey & .91 & 1.22 & .99 & .92 & 5.51 & .63 & 2.32 & 2.58 & 75 & 5.54 \\
\hline UK & .95 & .96 & .94 & .94 & 7.13 & .44 & 3.15 & 3.12 & 10 & 7.56 \\
\hline Ukraine & 1.18 & 2.03 & 1.10 & 1.18 & 3.89 & .73 & 1.85 & 2.05 & 73 & 5.65 \\
\hline$M$ & 1.04 & 1.27 & 1.04 & 1.02 & 6.55 & .49 & 2.81 & 2.95 & 30.38 & 7.05 \\
\hline SD & .09 & .44 & .08 & .07 & 1.12 & .17 & .48 & .38 & 22.90 & .79 \\
\hline
\end{tabular}

RD scores $>1$ indicate relative disadvantage for older (60-75) compared to younger (30-45) people. $L$ scores $>1$ indicate better quality of living conditions for both young and old (with the exception of $L_{\text {prejudice}}$ ). Higher AgeWatch index score indicates better situation of older adults in the country

Table 2 Correlations between the macro-level indicators and the outcome variables $(N=29)$

\begin{tabular}{lccc}
\hline & Relative disadvantage & Age-matched & AgeWatch \\
\hline Relative disadvantage & & & \\
Age-matched & $-.54 * * *$ & & \\
AgeWatch & $.49^{* * *}$ & $-.79 * * *$ & \\
Happiness & $-.37 * * *$ & $.92^{* * *}$ & $-.80^{* * * *}$ \\
\hline
\end{tabular}

$* * * p<.001$

Table 2 summarizes the correlations between macrolevel predictors and the outcome variable, happiness, at the macro-level. The relative age disadvantage index was significantly and negatively correlated with the average age-matched levels of living conditions in the country and with happiness. It was positively correlated with the AgeWatch index. There also was a negative correlation between the AgeWatch index and the average age-matched 
levels of living conditions in the country. The average agematched levels of living conditions in the country were positively correlated with happiness, whereas the AgeWatch index was negatively correlated with happiness.

Multi-level analyses we conducted multi-level regression analyses with happiness as an outcome variable. Table 3 details the results of the multi-level regression analyses. The unconditional model of happiness resulted in an intra-class correlation (ICC; percentage of variance attributed to macro-level predictors) of $13.9 \%$.

In the second model, which accounted for micro-level predictors, as age increased, happiness decreased. Individuals of higher levels of education and women were more likely to report higher levels of happiness. The next model addressed random intercept and slope, with microlevel predictors. Results remained consistent.

Subsequently, macro-level predictors were entered into the model. Higher levels of age-matched quality of living conditions (better overall quality of life) were associated with higher levels of happiness. Relative old age disadvantage (the situation of older adults is worse than that of younger adults) was associated with greater happiness. The
AgeWatch index was negatively correlated with happiness, so that in countries characterized by better situation of older adults, individuals reported greater happiness.

In the final analysis, we examined cross-level interactions. There was a significant interaction between relative age disadvantage and age, suggesting that relative age disadvantage is particularly beneficial for younger adults; as old age disadvantage increases, the negative relationship between age and happiness strengthens. The age-matched quality of living conditions was positively correlated with happiness, and the AgeWatch index was negatively correlated with happiness. See Fig. 1 for details concerning the interaction effect.

\section{Discussion}

The majority of past research has focused primarily on age inequality or ageism at the level of the individual (Palmore 2015) or at the level of social interactions (Ng 1998). The present study is one of very few studies to address age inequalities at the national level. The advantage of

Table 3 Multi-level regression analyses, with happiness as an outcome $(N=56,222)$

\begin{tabular}{|c|c|c|c|c|c|}
\hline & $\begin{array}{l}\text { Model } 1 \text { estimate } \\
\text { (SE) }\end{array}$ & $\begin{array}{l}\text { Model } 2 \text { estimate } \\
\text { (SE) }\end{array}$ & $\begin{array}{l}\text { Model } 3 \text { estimate } \\
\text { (SE) }\end{array}$ & $\begin{array}{l}\text { Model } 4 \text { estimate } \\
\text { (SE) }\end{array}$ & $\begin{array}{l}\text { Model } 5 \text { estimate } \\
\text { (SE) }\end{array}$ \\
\hline Intercept & $7.05 * * *(.15)$ & $6.91 * * *(.16)$ & $6.93 * * *(.16)$ & $6.89 * * *(.08)$ & $6.89 * * *(.06)$ \\
\hline \multicolumn{6}{|l|}{ Micro-level } \\
\hline Age (years) & & $-.01 * * *(.00)$ & $-.01 * * *(.00)$ & $-.01 * * *(.00)$ & $-.01 * * *(.01)$ \\
\hline Gender $(1=$ men; $2=$ women $)$ & & $.05 * *(.02)$ & $.06 * *(.02)$ & $.06 * * *(.02)$ & $.06 * * *(.02)$ \\
\hline Education (years) & & $.05 * * *(.00)$ & $.04 * * *(.00)$ & $.05 * * *(.00)$ & $.04 * * *(.00)$ \\
\hline \multicolumn{6}{|l|}{ Macro-level } \\
\hline Age-matched $(L)$ & & & & $.73 * * *(.09)$ & $.73 * * *(.09)$ \\
\hline Relative disadvantage (RD) & & & & $.40 * *(.07)$ & $.09(.08)$ \\
\hline AgeWatch & & & & $-.01 *(.00)$ & $-.01 *(.01)$ \\
\hline \multicolumn{6}{|l|}{ Cross-level interactions } \\
\hline L* age & & & & & Ns \\
\hline RD*age & & & & & $-01 * * *(.00)$ \\
\hline AgeWatch*age & & & & & n.s. \\
\hline $\mathrm{ICC}(\%)$ & 13.9 & 16.2 & 16.4 & 4.2 & 2.3 \\
\hline
\end{tabular}

$* p<.05, * * p<.01, * * * p<.001$; relative age inequality (relative disadvantage, RD), age-matched quality of living conditions (level, $L$ ). $n s$ non-significant, thus, not included in the final model presented

Model 1 Happiness $\mathrm{ij}_{\mathrm{j}}=\beta_{0 \mathrm{j}}+\mathrm{e}_{\mathrm{ij}} \cdot \beta_{0 \mathrm{j}}=\gamma_{00}+u_{\mathrm{oj}}$

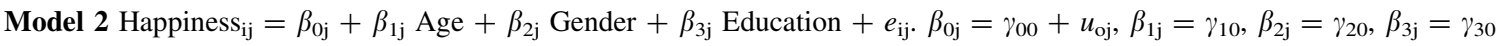

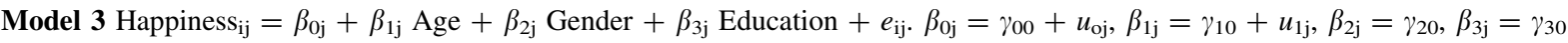

Model 4 Happiness Hij $=\beta_{0 \mathrm{j}}+\beta_{1 \mathrm{j}}$ Age $+\beta_{2 \mathrm{j}}$ Gender $+\beta_{3 \mathrm{j}}$ Education $+e_{\mathrm{ij}}$. $\beta_{0 \mathrm{j}}=\gamma_{00}+\gamma_{01} L_{\mathrm{j}}+\gamma_{02} \mathrm{RD}_{\mathrm{j}}+\gamma_{03}$ AgeWatch $_{\mathrm{j}}+u_{\mathrm{oj}}, \beta_{1 \mathrm{j}}=-$ $\gamma_{10}+u_{1 \mathrm{j}}, \beta_{2 \mathrm{j}}=\gamma_{20}, \beta_{3 \mathrm{j}}=\gamma_{30}$

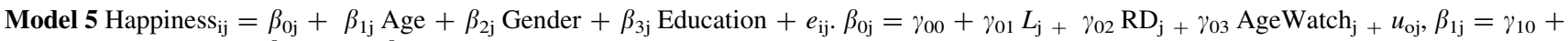
$\gamma_{11} L_{j}+\gamma_{12} R_{j}+u_{1 j}, \beta_{2 j}=\gamma_{20}, \beta_{3 j}=\gamma_{30}$ 


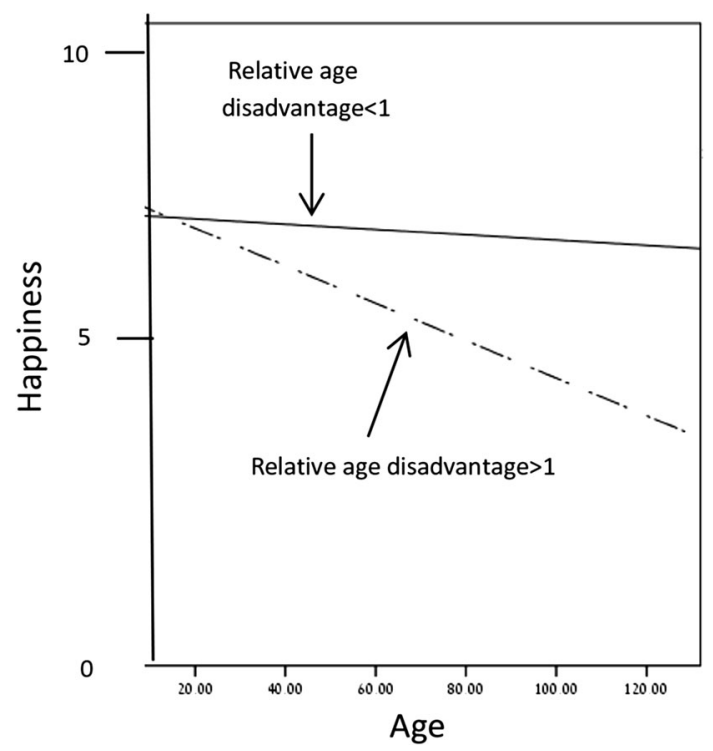

Fig. 1 The relationship between happiness and age, as a function of relative age disadvantage at the country level. Relative age disadvantage $>1$ means that the status of younger adults is better than that of older adults

examining age inequalities at the national level is that this potentially can change public discourse by pointing to relative age disadvantage as a social phenomenon, rather than a phenomenon at the level of the individual. Such a portrayal allows examining age inequalities in relation to policies and planning.

In contrast to existing indicators of the status of older adults in society, which tend to focus on the absolute status of older adults and disregard relative age inequality within a single country (Zaidi 2014), the present study evaluated the utility of indicators of relative age disadvantage. The benefit of such indicators is that they point to a relative disadvantage of older people in contrast to younger people, rather than to the absolute status of older adults in society. The proposed indicators compare not only older adults in different countries (i.e. the end product), but also older versus younger adults within the same country (i.e. inequality). Developing such relative indicators is crucial because they provide information about specific age-related differences in structural living conditions, regulations, treatment, and behaviours towards older people.

It is important to note, however, that there were highly significant correlations between the relative age disadvantage measure, the overall quality of living conditions in the country, and the AgeWatch index. This suggests that relative age disadvantage is more likely to occur in countries that are characterized by worse living conditions of both young and old. Hence, even though the measure of relative age disadvantage provides a unique contribution to our understanding of inequalities, it happens in context, so that more affluent countries are likely to be characterized by less age disadvantage and vice versa.

We selected four indicators to represent relative old age disadvantage. These indicators reflect the personal, relational, and collective needs proposed by Prilleltensky (2008) as potentially important for people's well-being. It is important to note, however, that the selection of these four indicators was somewhat arbitrary, as many other theories could have been used to guide the selection. Moreover, the selection of variables to represent the four indicators was guided by the availability of items in the ESS. It also is important to note that perceived exposure to prejudice appeared to have limited cross-country variability (e.g. low ICC), suggesting that this might not be an ideal indicator at the macro-level. Hence, future research will benefit from identifying other potential indicators of relative age inequality.

The descriptive analyses provide an inconclusive statement regarding the status of older versus younger adults in society. None of the indicators showed a consistent pattern. Of note is the fact that two indicators which resulted in mixed findings regarding the relative disadvantage of older adults address perceived availability of health services and perceived age-based prejudice. This may seem surprising given past research which has consistently found ageism in the healthcare system (Eymard and Douglas 2012) and a general tendency towards negative attitudes towards older adults (Kite and Johnson 1988). Possibly, some age inequalities in society are not interpreted as indicative of prejudice, but, instead, might be perceived as justified or natural due to the internalization of negative old age stereotypes (Kornadt and Rothermund 2012; Levy 2009; Rothermund and Brandtstädter 2003). This finding supports a distinction between objective versus subjective prejudice (Ayalon 2016; Ayalon and Gum 2011).

Nevertheless, our findings suggest that the proposed indicators provide unique information that is not captured by absolute indicators of living conditions within a country. Our findings clearly document an interaction between relative age disadvantage and age. This suggests that relative old age disadvantage is particularly detrimental for happiness as age increases. It is important to note, however, that the interaction effect resulted only in a minor change in the overall variance attributed to the macro-level. Hence, it should be viewed with caution. In addition, greater happiness was associated with higher levels of the agematched index and negatively correlated with the AgeWatch index, indicating that happiness is greater in countries of better overall quality of living conditions of both young and old as well as in countries of better conditions of older adults.

The present findings should be reviewed in light of the limitations of this study. First, the study was restricted to 
countries that participated in the fourth wave of the ESS. Possibly, a larger and more diverse pool of countries would have resulted in somewhat different findings. Second, this is a cross-sectional analysis. Hence, we cannot distinguish between age effects and cohort effects. Moreover, significant macro-level relations do not indicate a causal effect.

It is also important to note that the macro-level indicators selected were all based on self-report. They do not reflect the objective situation of older adults in society, but rather reflect the perceptions of both young and old people regarding their status. The decision to focus on subjective reports is fuelled by past research, which has demonstrated the importance of subjective indicators and potentially their improved performance compared with objective indicators (Adler et al. 2000; Ayalon 2008; Barrett and Montepare 2015). Furthermore, the use of a composite score should be viewed with caution as the four indicators do not measure a homogenous construct. Nonetheless, the decision to use a composite score rather than four separate indicators aimed to increase the brevity and clarity of the paper. Finally, it is important to note that the decision to compare two specific age groups was somewhat arbitrary given the fact that there is no clear-cut consensus concerning the ending of youth or the beginning of old age across countries or even within countries (Ayalon et al. 2014).

Despite its limitations, this is one of very few studies to address age inequality at the national level and to emphasize the notion of relative age disadvantage as a potentially important indicator that deserves further attention and research. Our findings show that old age disadvantage is particularly detrimental for one's happiness as age increases.

Acknowledgements Funding was provided by European Cooperation in Science and Technology (Grant No. IS1402).

\section{References}

Adler NE, Epel ES, Castellazzo G, Ickovics JR (2000) Relationship of subjective and objective social status with psychological and physiological functioning: preliminary data in healthy, white women. Health Psychol 19:586

AgeInternational (2015). Global rankings table. Accessed online: http://www.helpage.org/global-AgeWatch/population-ageingdata/global-rankings-table/

Ayalon L (2008) Subjective socioeconomic status as a predictor of long-term care staff burnout and positive caregiving experiences. Int Psychogeriatr 20:521-537

Ayalon L (2014) Perceived age, gender, and racial/ethnic discrimination in Europe: results from the European social survey. Educ Gerontol 40:499-517

Ayalon L (2016) Perceived age discrimination: A precipitator or a consequence of depressive symptoms? J Gerontol B: Psychol Sci Soc Sci:gbw101

Ayalon L, Gum AM (2011) The relationships between major lifetime discrimination, everyday discrimination, and mental health in three racial and ethnic groups of older adults. Aging Ment Health 15:587-594

Ayalon L, Doron I, Bodner E, Inbar N (2014) Macro-and micro-level predictors of age categorization: results from the European social survey European. Eur J Ageing 11:5-18

Barrett AE, Montepare JM (2015) "It's about time": applying life span and life course perspectives to the study of subjective age. Annu Rev Gerontol Geriatrics 35:55-77

Blanchflower DG, Oswald AJ (2008) Is well-being U-shaped over the life cycle? Soc Sci Med 66:1733-1749. doi:10.1016/j.socscimed. 2008.01.030

Boudiny K (2013) 'Active ageing': from empty rhetoric to effective policy tool. Ageing Soc 33:1077-1098

Burchardt T (2006) Foundations for measuring equality: A discussion paper for the equalities review LSE STICERD Research Paper No CASE111. http://eprints.lse.ac.uk/6236/1/Foundations_for_ measuring_equality_A_discussion_paper_for_the_Equalities_ Review.pdf

Chatterji S, Byles J, Cutler D, Seeman T, Verdes E (2015) Health, functioning, and disability in older adults-present status and future implications. Lancet 385:563-575

Cherubini A, Signore SD, Ouslander J, Semla T, Michel J-P (2010) Fighting against age discrimination in clinical trials. J Am Geriatr Soc 58:1791-1796. doi:10.1111/j.1532-5415.2010. 03032.x

Dahlin J, Härkönen J (2013) Cross-national differences in the gender gap in subjective health in Europe: Does country-level gender equality matter? Soc Sci Med 98:24-28

Eaton AA, Visser PS, Krosnick JA, Anand S (2009) Social power and attitude strength over the life course. Pers Soc Psychol Bull 35:1646-1660

ESS Round 4: European Social Survey Round 4 Data (2008). Data file edition 4.4

Eymard AS, Douglas DH (2012) Ageism among health care providers and interventions to improve their attitudes toward older adults: an integrative review. J Gerontol Nurs 38:26-35

Geske Dijkstra A (2006) Towards a fresh start in measuring gender equality: a contribution to the debate. J Hum Dev 7:275-283

Hartog J, Oosterbeek H (1998) Health, wealth and happiness: why pursue a higher education? Econ Educ Rev 17:245-256

Hosseinpoor AR, Bergen N, Schlotheuber A (2015) Promoting health equity: WHO health inequality monitoring at global and national levels. Glob Health Action 8

Jermyn D (2013) Past their prime time?: women, ageing and absence on british factual television. Crit Stud Telev Int J Telev Stud 8:73-90

Jütting JP, Morrisson C, Dayton-Johnson J, Drechsler D (2008) Measuring gender (in) equality: the OECD gender, institutions and development data base. J Hum Dev 9:65-86

Kite ME, Johnson BT (1988) Attitudes toward older and younger adults: a meta-analysis. Psychol Aging 3:233-244

Kornadt AE, Rothermund K (2012) Internalization of age stereotypes into the self-concept via future self-views: a general model and domain-specific differences. Psychol Aging 27:164

Kornadt AE, Rothermund K (2015) Views on aging: domain-specific approaches and implications for developmental regulation. Ann Rev Gerontol Geriatr 35:121-144

Kotter-Grühn D, Hess TM (2012) The impact of age stereotypes on self-perceptions of aging across the adult lifespan. J Gerontol B Psychol Sci Soc Sci 67:563-571. doi:10.1093/geronb/gbr153

Lachman ME, Teshale S, Agrigoroaei S (2015) Midlife as a pivotal period in the life course: balancing growth and decline at the crossroads of youth and old age. Int J Behav Dev 39:20-31. doi:10.1177/0165025414533223

Lakra DC, Ng R, Levy BR (2012) Increased longevity from viewing retirement positively. Ageing Soc 32:1418-1427 
Levy BR (2009) Stereotype embodiment: a psychosocial approach to aging. Curr Dir Psychol Sci 18:332-336

Levy BR, Slade MD, Kunkel SR, Kasl SV (2002) Longevity increased by positive self-perceptions of aging. J Pers Soc Psychol 83:261

Lynch SM (2003) Cohort and life-course patterns in the relationship between education and health: a hierarchical approach. Demography 40:309-331

MacGregor D (2006) Editorial: neglecting elders in the workplace: civil society organizations, ageism, and mandatory retirement. Can J Aging 25:243-246

McNally M, Lahey W (2015) Frailty's place in ethics and law: some thoughts on equality and autonomy and on limits and possibilities for aging citizens. Interdiscip Top Gerontol Geriatr 41:147-185

Mégret F (2011) The human rights of older persons: a growing challenge human rights. Law Rev 11:37-66. doi:10.1093/hrlr/ ngq050

$\mathrm{Ng} \mathrm{SH}$ (1998) Social psychology in an ageing world: ageism and intergenerational relations. Asian J Soc Psychol 1:99-116

Palmore E (2015) Ageism comes of age. J Gerontol B Psychol Sci Soc Sci 70:873-875. doi:10.1093/geronb/gbv079

Prilleltensky I (2008) The role of power in wellness, oppression, and liberation: the promise of psychopolitical validity. J Community Psychol 36:116-136. doi:10.1002/jcop.20225

Rathmann K et al (2015) Macro-level determinants of young people's subjective health and health inequalities: a multilevel analysis in 27 welfare states. Maturitas 80:414-420
Rothermund K, Brandtstädter J (2003) Age stereotypes and self-views in later life: evaluating rival assumptions. Int $\mathrm{J}$ Behav Dev 27:549-554. doi:10.1080/01650250344000208

Schermuly CC, Deller J, Büsch V (2013) A research note on age discrimination and the desire to retire: the mediating effect of psychological empowerment. Res Aging

Shortt S (2001) Venerable or vulnerable? Ageism in health care Journal of health services. Res Policy 6:1-2

Snyder K (2015) Is younger really better? Age differences in emotion perception

Vaillant G (2011) The happiness effect. Bull World Health Organ $89: 246-247$

Voss P, Wolff JK, Rothermund K (2016) Relations between views on ageing and perceived age discrimination: a domain-specific perspective. Eur J Ageing:1-11

Westerhof GJ et al (2014) The influence of subjective aging on health and longevity: a meta-analysis of longitudinal data. Psychol Aging 29:793

Wilkinson RG, Pickett KE (2006) Income inequality and population health: a review and explanation of the evidence. Soc Sci Med 62:1768-1784

Wilkinson RG, Pickett KE (2007) The problems of relative deprivation: why some societies do better than others. Soc Sci Med 65:1965-1978. doi:10.1016/j.socscimed.2007.05.041

Yuan ASV (2007) Perceived age discrimination and mental health. Soc Forces 86:291-311

Zaidi A (2014) Enabling environments for active and healthy ageing in EU countries. Gerontechnology 12:201-208 